Full Length Article

\title{
Identification and S-metolachlor-safening Effects of Compounds Extracted from Ligusticum chuanxiong on Rice
}

\author{
Jingbo Li ${ }^{1,2}$, Wei Zheng ${ }^{1,2}$, Yanhui Wang ${ }^{3}$, Hailin Cai ${ }^{4}$, Chenzhong Jin ${ }^{1,2}$, Xiu Liu ${ }^{1,2}$ and Lianyang Bai ${ }^{1,5^{*}}$ \\ ${ }^{1}$ Department of Agriculture and Biotechnology, Hunan University of Humanities, Science and Technology, Loudi 417000, China \\ ${ }^{2}$ Collaborative Innovation Center for Field Weeds Control, Loudi 417000, China \\ ${ }^{3}$ Institute of Plant Protection, Guangxi Academy of Agricultural Science, Nanning 530007, China \\ ${ }^{4}$ Tobacco Monopoly Bureau of Changsha, Changsha 410000, Hunan, China \\ ${ }^{5}$ Hunan Academy of Agricultural Science, Changsha 410000, China \\ *For correspondence: bailianyang2005@yahoo.com.cn
}

\begin{abstract}
In this study, the effects of Ligusticum chuanxiong extract as herbicide safeners were determined on glutathione-S-transferase (GST) activity of rice crop. Two main extract compounds, Z-ligustilide and senkyunolide A, were identified by high performance liquid chromatography and liquid chromatography-mass spectrometry. In both bioassays conducted in agar and soil, the whole L. chuanxiong extract, as well as two active components individually were effective in safening the growth of rice seedlings against S-metolachlor toxicity. Z-Ligustilide was a better safener than senkyunolide A, and both compounds were more protective of shoots than roots. After herbicide-inhibited rice seedlings were treated with Z-ligustilide, GST activity significantly increased, suggesting the safening effect of this L. chuanxiong extract component involves GST. C 2016 Friends Science Publishers
\end{abstract}

Keywords: Herbicide safeners; Z-ligustilide; Glutathione-S-transferase; S-metolachlor

\section{Introduction}

Crop sensitivity to herbicides often causes severe reductions in crop production. Herbicide injury has affected crop growth on more than 50 million acres in China, reducing crop yields by $30-50 \%$. Safeners play a crucial role in protecting crops from herbicide injury and can extend the application of some herbicides to more sensitive crops. Nearly 20 different safeners have been commercialized since the first safener, 1,8-naphthalic anhydride, was reported in 1969 (Kramer and Schirmer, 2007). Most aim to protect monocots from herbicide injury. For example, fenchlorazole-ethyl and mefenpyr-diethyl are used to safen aryloxyphenoxypropionates used on wheat and barley (Cummins et al., 2009) and cloquintocet-mexyl can protect wheat from acetyl-CoA carboxylase inhibition (Brazier et al., 2002; Hofer et al., 2006). Benoxacor can be mixed with chloroacetamides to ensure corn safety (Davies and Caseley, 1999), while dichlormid and AD-67 mixed with acetochlor can achieve similar protection (Ekler et al., 1993; Brazier et al., 2002). Representative safeners protecting sorghum from chloroacetamide injury include fluxofenim, cyometrinil, oxabetrinil, and flurozole (Leif et al., 1987; Bussler, 1996; Gronwald and Plaisance, 1998). Injury to rice caused by chloroacetamides can be alleviated by the safener fenclorim (Wu et al., 1999; DeRidder et al., 2002; Deng and Hatzios, 2002a), while isoxadifen-ethyl protects rice against sulfonylurea, daimuron, cumyluron and dimepiperate herbicide injury (Kramer and Schirmer, 2007). However, the abovementioned safeners are only able to safen one herbicide in a single crop. Bayer-developed isoxadifen-ethyl, on the other hand, takes herbicide safeners to a new level by safening multiple herbicides with various modes of action in multiple crops.

Chloroacetamides are a widely-used herbicide for controlling monocot weeds in Chinese rice fields. For example, pretilachlor is often applied in combination with fenclorim to prevent injury to rice. The chloroacetamide Smetolachlor is highly efficient in controlling monocot weeds, and rarely used in rice fields due to its toxicity to rice seedlings. In this study, we aimed to extend the application of S-metolachlor to rice by identifying a proper safener. Considering natural safeners are more environmentally friendly than synthetic ones, we screened botanical materials for compounds with the ability to safen S-metolachlor for application on rice. Of three plant species validated to protect rice from S-metolachlor injury in our previous study, Ligusticum chuanxiong (L. chuanxiong) was chosen for use in the current study. A L. chuanxiong extract was obtained by $\mathrm{CO}_{2}$ supercritical fluid extraction $\left(\mathrm{CO}_{2}-\mathrm{SFE}\right)$ and main active components were identified by high performance liquid chromatography (HPLC) and liquid chromatography-mass

To cite this paper: Li, J., W. Zheng, Y. Wang, H. Cai, C. Jin, X. Liu and L. Bai, 2016. Identification and S-metolachlor-safening effects of compounds extracted from Ligusticum chuanxiong on rice. Int. J. Agric. Biol., 18: 698-702 
spectrometry (LC-MS). Rice safening assays were conducted using the whole extract and two commercially available $L$. chuanxiong extract active compounds. In particular, potential effect(s) on glutathione- $S$-transferase (GST) activity was investigated with respect to safening against S-metolachlor injury of rice.

\section{Materials and Methods}

\section{Materials and Equipment}

Sun-dried L. chuanxiong was purchased from LBX Pharmacy (Changsha, China). Analytical grade Smetolachlor (97\%) was purchased from Nutrichem Laboratory Co. Ltd. (Beijing, China). Z-ligustilide and senkyunolide A were purchased from Yaji Biotechnology Co. Ltd. (Shanghai, China). The Shimadzu HPLC system (Kyoto, Japan) included a SPD-20A Prominence UV/VIS detector, two LC-20AT pumps, a Shimadzu LC solution workstation, and a CNW C 18 column $(4.6 \times 250 \mathrm{~mm}, 5 \mu \mathrm{m})$. The Agilent 1100 LC-MSD used was connected to a ZORBAX Extend $\mathrm{C}_{18}$ column $(4.6 \times 250 \mathrm{~mm}, 5 \mu \mathrm{m})$. The $\mathrm{CO}_{2}$-SFE apparatus (HA231-50-06) included a $\mathrm{CO}_{2}-$ supplying steal bottle, pressure-control system (0-50 MPa), temperature controller $\left(0-95^{\circ} \mathrm{C}\right)$, separator and an extraction tank (Huaan Super Critical Extraction Co. Ltd., Nantong, China). Lastly, a Shimadzu UV mini-1240 spectrophotometer was also used.

\section{L. chuanxiong Extract Preparation}

Crushed L. chuanxiong (6 kg) was sieved $(2 \mathrm{~mm}$ pore diameter), dehydrated in a freeze-dryer at $-40^{\circ} \mathrm{C}$ and subjected to $\mathrm{CO}_{2}$-SFE as follows: $\mathrm{CO}_{2}$ extraction was done in a $5 \mathrm{~L}$ extraction tank at $50^{\circ} \mathrm{C}$ and $35 \mathrm{MPa}$, followed by separation from $\mathrm{CO}_{2}$ in a separator at $55^{\circ} \mathrm{C}$ and $8 \mathrm{MPa}$. The extract $(0.2 \mathrm{~kg})$ was stored at $-20^{\circ} \mathrm{C}$ until further analysis.

\section{HPLC and LC-MS Extract Analysis}

The LC-MS mobile phase consisted of $6: 4(\mathrm{v} / \mathrm{v}) \quad 0.1 \%$ trifluoroacetic acid and acetonitrile, and the extract $(10 \mu \mathrm{l}$ injection volume) was eluted for $60 \mathrm{~min}$ at $1 \mathrm{~mL} \cdot \mathrm{min}^{-1}$. The extract was analyzed in positive ion mode using an APCI ion source at $120^{\circ} \mathrm{C}$, a nebulizer pressure of $35 \mathrm{psi}, 350^{\circ} \mathrm{C}$ desolvation and $8 \mathrm{~L} \cdot \mathrm{min}^{-1}$ dry gas $\left(\mathrm{N}_{2}\right)$ flow rate. The relative molecular masses of major components obtained by LC-MS were then matched with known $L$. chuanxiong compounds.

The identification of extract components was verified by HPLC using commercially available purified compounds. The extract was dissolved in ethyl acetate and subjected to HPLC ( $20 \mu \mathrm{L}$ injection volume) at $35^{\circ} \mathrm{C}$ and $254 \mathrm{~nm}$. The mobile phase consisted of water and acetonitrile, and HPLC was completed in gradient elution mode at a flow rate of 1 $\mathrm{mL} \cdot \mathrm{min}^{-1}$ as follows: 60 to $52 \%$ water for $40 \mathrm{~min}, 52$ to $60 \%$ water for $15 \mathrm{~min}$ and $60 \%$ water for $5 \mathrm{~min}$.

\section{S-Metolachlor Safening Bioassays of Rice Cultivated in Agar and Soil}

Rice seeds Zhuliangyou-90: indica type) purchased from Nongfeng Seed Industry Co. Ltd. (Changsha, China) were germinated according to a previous study (Deng and Hatzios, 2002a). Uniformly-germinated seeds were grown in $0.2 \%$ $(\mathrm{m} / \mathrm{m})$ agar $(150 \mathrm{~mL})$ containing the appropriate chemical treatment in a $28^{\circ} \mathrm{C}$ incubator without light for $5 \mathrm{~d}$. The safening treatment included a mixture of S-metolachlor and L. chuanxiong extract or commercially available Z-ligustilide or senkyunolide A dissolved in $1 \mathrm{ml}$ acetone and dispersed in the agar. Agar containing S-metolachlor dissolved in $1 \mathrm{ml}$ acetone without safeners or extract was used as the herbicide treatment, while $1 \mathrm{~mL}$ acetone alone was used as control. Experiments were replicated three times. The shoots and roots of rice seedlings treated with a mixture of Z-ligustilide and S-metolachlor were harvested separately, frozen in liquid nitrogen and stored at $-70^{\circ} \mathrm{C}$ until use for the determination of GST activity.

Chemical-free soil was air-dried and then sifted (0.85 $\mathrm{mm}$ pore diameter). Uniformly germinated seeds were planted in $180 \mathrm{~g}$ of the sifted soil in plastic pots $(13 \times 8.5 \times 5$ $\mathrm{cm}$ ) and grown in an incubator with a 16/8 h (day/night) photoperiod at $28 / 26.5^{\circ} \mathrm{C}$ (day/night) and $7500 \mathrm{~lx}$ maximal illumination. For safening treatments, S-metolachlor mixed with the L. chuanxiong extract or commercially available Zligustilide or senkyunolide A was dissolved in $2 \mathrm{~mL}$ acetone and diluted to a final volume of $1 \mathrm{~L}$ with water. The nonionic chemical surfactant Tween-80 $(0.25 \%$ [v/v]) was used to maximize dispersion of the mixture in water (Deridder and Goldsbrough, 2006). The herbicide treatment included Smetolachlor, $0.2 \%$ acetone, and $0.25 \%$ Tween- 80 , while the control treatment only contained $0.2 \%$ acetone and $0.25 \%$ Tween-80. Each solution $(5 \mathrm{~mL})$ was poured into the plastic pots $2 \mathrm{~d}$ after rice seedling growth; bioassays were conducted $8 \mathrm{~d}$ after treatment. The experiment was replicated three times.

\section{Glutathione-S-transferase (GST) Activity}

Shoots and roots frozen in liquid nitrogen were ground into a powder and then extracted with $0.2 \mathrm{~mol} \cdot \mathrm{L}^{-1}$ Tris- $\mathrm{HCl}$ buffer ( $\mathrm{pH}$ 7.2) containing $5 \mathrm{mmol} \cdot \mathrm{L}^{-1}$ 2-mercaptoethanol, 1 $\mathrm{mmol} \cdot \mathrm{L}^{-1}$ ethylene diamine tetraacetic acid, and $7.5 \%$ polyvinylpolypyrrolidone. After centrifugation of the extract at 20,000 $\times \mathrm{g}$ for $30 \mathrm{~min}$, the supernatant was harvested. Protamine sulfate at $10 \%(\mathrm{v} / \mathrm{v})$ was then added to the supernatant to precipitate nucleic acids. Finally, an equal volume of ammonium sulfate was added to the supernatant to precipitate proteins, which were collected and suspended in $1 \mathrm{ml}$ Tris- $\mathrm{HCl}(\mathrm{pH} 7.2)$ as an enzyme solution (Deng and Hatzios, 2002a).

The enzyme reaction system included $25 \mu \mathrm{L}$ enzyme solution, $225 \mu \mathrm{L}$ of $3.3 \mathrm{mmol} \cdot \mathrm{L}^{-1}$ glutathione and $3 \mathrm{~mL}$ of $0.1 \mathrm{~mol} \cdot \mathrm{L}^{-1}$ phosphate buffer ( $\left.\mathrm{pH} 7.4\right) ; 25 \mu \mathrm{L}$ of $30 \mathrm{mmol} \mathrm{L}^{-1}$ 
1-chloro-2,4-dinitrobenzene was used to activate the reaction, and changes in absorbance were measured within 2 $\min$ at $340 \mathrm{~nm}$. A non-enzyme reaction control system was used to eliminate the impact of the reaction apart from enzymes. Bio-Rad protein concentration determination was completed using bovine serum albumin as a standard.

\section{Statistical Analysis}

Data were analyzed using SPSS (version 18.0.0) and differences in different treatments were determined by ANOVA. Means were separated using Least Significant Difference test at $5 \%$ level of significance.

\section{Results}

\section{Identification of Main Extract Active Compounds}

According to LC-MS, the relative molecular masses of four main extract components (1-4) were 194, 162, 192 and 190, respectively (Fig. 1). Compared to the relative molecular masses of known $L$. chuanxiong compounds, components 3 and 4 corresponded to Z-ligustilide and senkyunolide A, respectively, while components 1 and 2 were unmatched. HPLC analysis showed that retention times for components 3 and 4 were 33.8 and $50.7 \mathrm{~min}$., respectively corresponding to pure Z-ligustilide and senkyunolide A, respectively (Fig. 2). The identity of components 1 and 2 remained unknown.

\section{Safening Effect on Rice in Agar}

S-Metolachlor evidently inhibited rice growth at a concentration of $0.20 \mathrm{mg} \cdot \mathrm{L}^{-1}$ in agar. Shoot height and root length declined to $70 \%$ and $50 \%$ of control, respectively (Table 1 and 2). The herbicide-inhibitive effect was significantly reversed by the L. chuanxiong extract (Table 1) in a concentration-dependent manner from $3.33-13.33 \mathrm{mg} \cdot \mathrm{L}^{-}$ 1; higher extract concentrations $\left(26.67-53.33 \mathrm{mg} \cdot \mathrm{L}^{-1}\right)$ were less effective. Both commercially available Z-ligustilide and senkyunolide A were able to safen S-metolachlor applied to rice in a similar manner and concentration range (Table 2). Z-Ligustilide produced total reversion of S-metalochlor herbicide injury of shoots and roots at $4 \mathrm{mg} \cdot \mathrm{L}^{-1}$, but was phytotoxic to rice at concentrations ranging from $8-16 \mathrm{mg} \cdot \mathrm{L}-$ ${ }^{1}$. A similar trend was presented by senkyunolide A, though it was somewhat less protective than Z-ligustilide.

\section{Safening Effect on Rice in Soil}

S-Metolachlor severely inhibited the growth of rice in soil ( $30 \%$ of control) at a concentration of $10 \mathrm{mg} \cdot \mathrm{L}^{-1}$ (Table 3 and 4). Safening treatments with $L$. chuanxiong extract (400 $\mathrm{mg} \cdot \mathrm{L}^{-1}$ ) and commercially available Z-ligustilide or senkyunolide A (both $120 \mathrm{mg} \cdot \mathrm{L}^{-1}$ ) reversed herbicideinhibited rice growth to 96,95 and $75 \%$ of control levels, respectively. However, their application at higher concentrations was less effective, as with agar-grown rice.
Table 1: $L$. chuanxiong extract safening of S-metolachlor applied to rice grown in agar

\begin{tabular}{lll}
\hline $\begin{array}{l}\text { Treatments } \\
\left(\mathrm{mg} \cdot \mathrm{L}^{-1} / \mathrm{mg} \cdot \mathrm{L}^{-1}\right)\end{array}$ & $\begin{array}{l}\text { Ratio in shoots } \\
\text { [extract/control }(\%)]\end{array}$ & $\begin{array}{l}\text { Ratio in roots } \\
\text { [extract/control }(\%)]\end{array}$ \\
\hline $\mathrm{A}(0.20)$ & $71.83 \pm 2.14 \mathrm{a}$ & $51.60 \pm 1.89 \mathrm{a}$ \\
$\mathrm{B} / \mathrm{A}(3.33 / 0.20)$ & $83.05 \pm 1.90 \mathrm{~b}$ & $78.34 \pm 4.29 \mathrm{~d}$ \\
$\mathrm{~B} / \mathrm{A}(6.67 / 0.20)$ & $92.09 \pm 2.30 \mathrm{c}$ & $89.51 \pm 1.53 \mathrm{e}$ \\
$\mathrm{B} / \mathrm{A}(13.33 / 0.20)$ & $100.45 \pm 1.01 \mathrm{~d}$ & $93.49 \pm 2.23 \mathrm{e}$ \\
$\mathrm{B} / \mathrm{A}(26.67 / 0.20)$ & $86.83 \pm 1.91 \mathrm{~b}$ & $67.69 \pm 3.18 \mathrm{c}$ \\
$\mathrm{B} / \mathrm{A}(53.33 / 0.20)$ & $83.25 \pm 2.97 \mathrm{~b}$ & $60.83 \pm 3.00 \mathrm{~b}$ \\
\hline Mean \pm standard deviation. Values sharing same letters differ non-
\end{tabular}
significantly $(\mathrm{P}>0.05)$. A: S-metolachlor; B: extract

Table 2: Z-Ligustilide and senkyunolide A safening of Smetolachlor applied to rice grown in agar

\begin{tabular}{lcc}
\hline $\begin{array}{l}\text { Treatments } \\
\left(\mathrm{mg} \cdot \mathrm{L}^{-1} / \mathrm{mg} \cdot \mathrm{L}^{-1}\right)\end{array}$ & $\begin{array}{l}\text { Ratio in shoots } \\
\text { [active compounds/control (\%)] }\end{array}$ & $\begin{array}{l}\text { Ratio in roots [active } \\
\text { compounds/control }(\%)]\end{array}$ \\
\hline $\mathrm{A}(0.20)$ & $71.83 \pm 2.14 \mathrm{a}$ & $53.94 \pm 1.40 \mathrm{a}$ \\
$\mathrm{B} / \mathrm{A}(1 / 0.20)$ & $84.63 \pm 2.11 \mathrm{c}$ & $79.35 \pm 2.90 \mathrm{~d}$ \\
$\mathrm{~B} / \mathrm{A}(2 / 0.20)$ & $96.73 \pm 3.70 \mathrm{~d}$ & $84.45 \pm 3.97 \mathrm{~d}$ \\
$\mathrm{~B} / \mathrm{A}(4 / 0.20)$ & $101.15 \pm 0.51 \mathrm{e}$ & $94.84 \pm 2.65 \mathrm{e}$ \\
$\mathrm{B} / \mathrm{A}(8 / 0.20)$ & $87.25 \pm 0.79 \mathrm{c}$ & $67.34 \pm 2.17 \mathrm{c}$ \\
$\mathrm{B} / \mathrm{A}(16 / 0.20)$ & $83.59 \pm 0.88 \mathrm{c}$ & $59.52 \pm 2.40 \mathrm{~b}$ \\
$\mathrm{C} / \mathrm{A}(1 / 0.20)$ & $79.23 \pm 1.29 \mathrm{~b}$ & $62.39 \pm 0.97 \mathrm{~b}$ \\
$\mathrm{C} / \mathrm{A}(2 / 0.20)$ & $84.92 \pm 4.50 \mathrm{c}$ & $70.52 \pm 0.78 \mathrm{c}$ \\
$\mathrm{C} / \mathrm{A}(4 / 0.20)$ & $84.34 \pm 1.19 \mathrm{c}$ & $81.12 \pm 1.13 \mathrm{~d}$ \\
$\mathrm{C} / \mathrm{A}(8 / 0.20)$ & $89.28 \pm 1.91 \mathrm{c}$ & $83.60 \pm 2.24 \mathrm{~d}$ \\
$\mathrm{C} / \mathrm{A}(16 / 0.20)$ & $88.16 \pm 1.69 \mathrm{c}$ & $81.36 \pm 6.13 \mathrm{~d}$ \\
\hline Mean \pm standard deviation. Values sharing same letters differ non- \\
significantly $(\mathrm{P}>0.05)$. A: S-metolachlor; B: Z-ligustilide; C: senkyunolide A
\end{tabular}

Table 3: $L$. chuanxiong extract safening of S-metolachlor applied to rice grown in soil

\begin{tabular}{lc}
\hline Treatments $\left(\mathrm{mg} \cdot \mathrm{L}^{-1} / \mathrm{mg} \cdot \mathrm{L}^{-1}\right)$ & Ratio in shoots [extract/control (\%)] \\
\hline A $(10)$ & $30.32 \pm 2.85 \mathrm{a}$ \\
B/A $(50 / 10)$ & $56.76 \pm 2.27 \mathrm{~b}$ \\
B/A $(100 / 10)$ & $69.13 \pm 3.86 \mathrm{c}$ \\
B/A $(200 / 10)$ & $88.52 \pm 3.42 \mathrm{e}$ \\
B/A $(400 / 10)$ & $95.84 \pm 3.33 \mathrm{f}$ \\
B/A (800/10) & $77.99 \pm 2.40 \mathrm{~d}$ \\
\hline
\end{tabular}

Mean \pm standard deviation. Values sharing same letters differ nonsignificantly $(\mathrm{P}>0.05)$. A: S-metolachlor; B: extract

Table 4: Z-Ligustilide and senkyunolide A safening of Smetolachlor applied to rice grown in soil

\begin{tabular}{lc}
\hline Treatments $\left(\mathrm{mg} \cdot \mathrm{L}^{-1} / \mathrm{mg} \cdot \mathrm{L}^{-1}\right)$ & Ratio in shoots [active compounds/control (\%)] \\
\hline $\mathrm{A}(10)$ & $29.55 \pm 1.95 \mathrm{a}$ \\
$\mathrm{B} / \mathrm{A}(15 / 10)$ & $63.11 \pm 5.51 \mathrm{~cd}$ \\
$\mathrm{~B} / \mathrm{A}(30 / 10)$ & $70.33 \pm 5.81 \mathrm{de}$ \\
$\mathrm{B} / \mathrm{A}(60 / 10)$ & $85.52 \pm 2.48 \mathrm{f}$ \\
$\mathrm{B} / \mathrm{A}(120 / 10)$ & $95.43 \pm 2.68 \mathrm{~g}$ \\
$\mathrm{~B} / \mathrm{A}(240 / 10)$ & $85.06 \pm 3.17 \mathrm{f}$ \\
$\mathrm{C} / \mathrm{A}(15 / 10)$ & $46.02 \pm 5.03 \mathrm{~b}$ \\
$\mathrm{C} / \mathrm{A}(30 / 10)$ & $59.97 \pm 7.97 \mathrm{c}$ \\
$\mathrm{C} / \mathrm{A}(60 / 10)$ & $66.99 \pm 3.38 \mathrm{cde}$ \\
$\mathrm{C} / \mathrm{A}(120 / 10)$ & $75.19 \pm 4.71 \mathrm{e}$ \\
$\mathrm{C} / \mathrm{A}(240 / 10)$ & $74.52 \pm 4.14 \mathrm{e}$ \\
\hline Mean \pm standard deviation. Values & sharing same letters differ non- \\
significantly (P>0.05). A: S-metolachlor; B: Z-ligustilide; C: senkyunolide A
\end{tabular}

\section{Effect of Z-ligustilide on GST Activity in Rice}

Results showed that there was no significant difference in 
Table 5: Glutathione-S-transferase (GST) activity in crude preparations from treated or untreated rice seedlings

\begin{tabular}{|c|c|c|c|c|}
\hline \multirow{2}{*}{$\begin{array}{l}\text { Treatments } \\
\left(\mathrm{mg} \cdot \mathrm{L}^{-1} / \mathrm{mg} \cdot \mathrm{L}^{-1}\right)\end{array}$} & \multicolumn{2}{|c|}{ Roots } & \multicolumn{2}{|c|}{ Shoots } \\
\hline & GST activities $\left(\mathrm{nmol} \mathrm{min}^{-1} \mathrm{mg}^{-1}\right)$ & Ratio (Z-ligustilide/control) & GST activity $\left(\mathrm{nmol} \mathrm{min}^{-1} \cdot \mathrm{mg}^{-1}\right)$ & Ratio (Z-ligustilide/control) \\
\hline Control & $135 \pm 80 a$ & - & $81 \pm 50 \mathrm{a}$ & - \\
\hline $\mathrm{A}(0.20)$ & $199 \pm 40 \mathrm{a}$ & 1.5 & $113 \pm 10 \mathrm{a}$ & 1.4 \\
\hline $\mathrm{B} / \mathrm{A}(1 / 0.20)$ & $465 \pm 31 \mathrm{~b}$ & 3.4 & $187 \pm 19 \mathrm{~b}$ & 2.3 \\
\hline $\mathrm{B} / \mathrm{A}(2 / 0.20)$ & $746 \pm 26 \mathrm{c}$ & 5.5 & $249 \pm 24 \mathrm{c}$ & 3.1 \\
\hline $\mathrm{B} / \mathrm{A}(4 / 0.20)$ & $1384 \pm 45 \mathrm{~d}$ & 10.3 & $363 \pm 10 \mathrm{~d}$ & 4.5 \\
\hline $\mathrm{B} / \mathrm{A}(8 / 0.20)$ & $1448 \pm 94 \mathrm{~d}$ & 10.7 & $365 \pm 22 \mathrm{~d}$ & 4.5 \\
\hline $\mathrm{B} / \mathrm{A}(16 / 0.20)$ & $1469 \pm 13 \mathrm{~d}$ & 10.9 & $377 \pm 34 \mathrm{~d}$ & 4.7 \\
\hline
\end{tabular}

Mean \pm standard deviation. Values sharing same letters differ non-significantly $(\mathrm{P}>0.05)$. A: S-metolachlor; B: Z-ligustilide

GST activity in rice shoots and roots between the herbicide treatment and control (Table 5). When herbicide-inhibition of shoot and root growth was reversed by Z-ligustilide, GST activity in both shoots and roots was significantly enhanced compared to control. Z-Ligustilide applied at concentrations ranging from $1-4 \mathrm{mg} \cdot \mathrm{L}^{-1}$ led to a gradual increase in GST activity in rice shoots (five-fold) and roots (11-fold) relative to control. GST activity in both shoots and roots was maintained at its highest level when Z-ligustilide was applied at concentrations greater than $4 \mathrm{mg} \cdot \mathrm{L}^{-1}$.

\section{Discussion}

Except for extensive medical studies of $L$. chuanxiong as a traditional Chinese medicine, many studies have focused on its agricultural applications as insecticides and fungicides. To our knowledge, this is the first report about the safening effect of the $L$. chuanxiong extract on rice treated with the herbicide S-metolachor. Using LC-MS, the relative molecular masses of both volatile and nonvolatile active compounds extracted from L. chuanxiong were determined. Two components were identified and confirmed by HPLC to be Z-ligustilide and senkyunolide A. Previous studies have reported application of these two compounds as insecticides (Miyazawa et al., 2004), fungicides (Meepagala et al., 2005; Sim and Shin, 2008) and medicinally to treat cardiovascular and cerebrovascular diseases and a menstrual disorder (Chu et al., 2011).

Few safeners have been developed for chloroacetamide application to rice, and none have proven effective against injury caused by S-metolachlor. In the present study, Zligustilide was found to be the most protective $L$. chuanxiong extract component by almost completely reversing Smetolachlor-inhibition of rice growth, demonstrating its potential as a safener for this chloroacetamide. As opposed to chemically synthesized safeners, application of botanicallyderived Z-ligustilide to rice fields is more environmentfriendly and avoids production of hazardous compounds from its chemical synthesis. Considering Z-ligustilide and senkyunolide A readily isomerize to other chemical compounds at room temperature (Cui et al., 2006), it is critical to stabilize their structures long enough to be effective. On the other hand, Z-ligustilide could produce even more effective safening compounds by modification of its functional group, which may represent alternative route

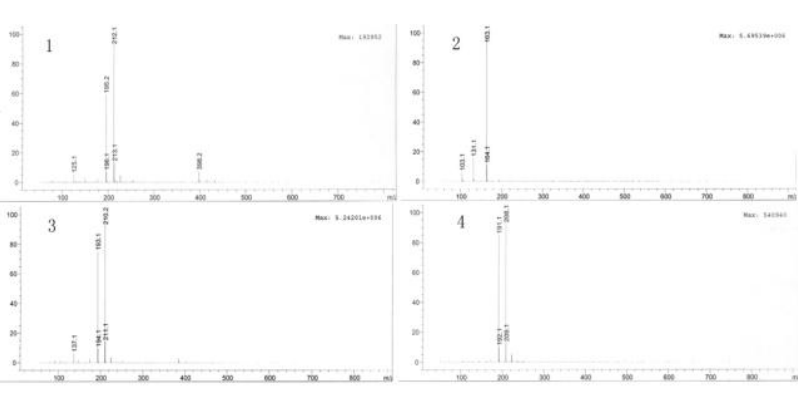

Fig. 1: Mass spectra of components 1-4

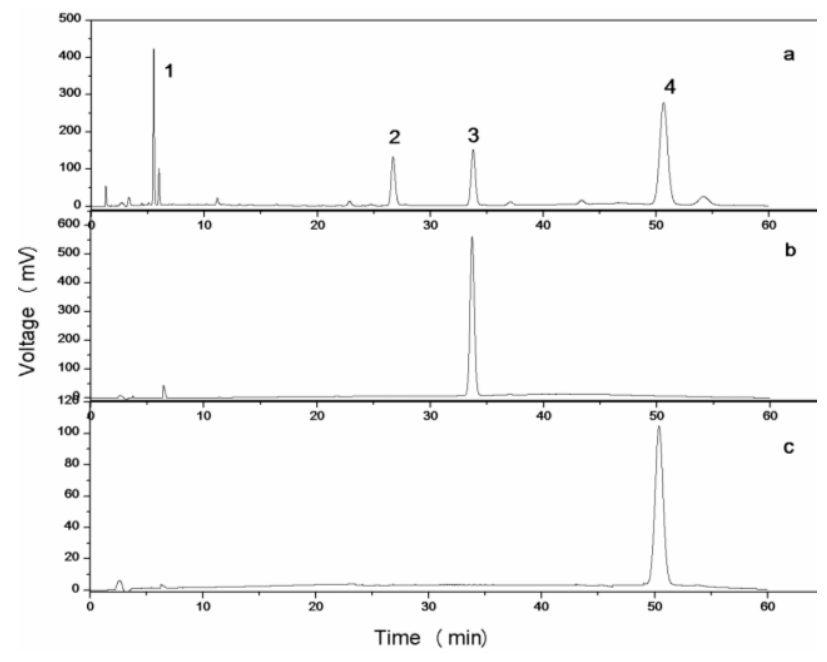

Fig. 2: HPLC chromatogram. (a): extract, (b): senkyunolide A, (c): Z-ligustilide

for developing new chloroacetamide safeners.

Recent studies on the mode of action of herbicide safeners have made it clear that safeners enhance degradation of herbicides to keep crops safe. In the degradation model, most hydrophobic herbicides are first transformed into hydrophilic compounds through reactions catalyzed by protective enzymes (e.g., oxidation by cytochrome P450 or conjugation by GST). Hydrophilic compounds can then be transported into the vacuole by ATP-binding cassette transporters or multidrug resistance-associated proteins and catabolized prior to their expulsion from the vacuole (Kolukisaoglu et al., 2002; Schröder and Collins, 2011). For 
example, fenclorim enhances the metabolism of pretilachlor by increasing GST activity in rice (Deng and Hatzios, 2002a). In fact, the GST isozyme OsGSTII-III plays an important role in the degradation of pretilachlor (Deng and Hatzios, 2002b). The accelerated metabolism of metazachlor in wheat by the safener BAS145-138 also involves an increase in GST activity (Riechers et al., 2010). Other studies have shown that safeners including fencorim, benoxacor and fluxofenim induce expression of GST in arabidopsis (DeRidder et al., 2002; Deridder and Goldsbrough, 2006). In present study, GST activity in rice shoots and roots was evidently increased by Z-ligustilide when applied with Smetolachlor. However, it should be noted that when used at high concentrations, Z-ligustilide can be phytotoxic to plant cells (Ho et al., 2009).

An added consideration is detoxification mediated by other enzymes. For example, the safener naphthalic anhydride has been shown to induce cytochrome P450 activation and enhance conversion of bensulfuron-methyl to 4-hydroxy-bensulfuron-methyl in rice (Deng and Hatzios, 2003). Liu (2010) also reported greater induction of cytochrome $\mathrm{P} 450$ activity by naphthalic anhydride than by fenclorim in rice and maize. Moreover, induction of $O$ glucosyltransferase activity by safener cloquintocet mexyl has been shown to be pertinent to the metabolism of xenobiotics with a hydroxyl functional group (Brazier et al., 2002). Edwards et al. (2011) suggested that metabolites with a hydroxyl functional group could be further $O$-glucosylated by $O$-glucosyltransferase. Therefore, future studies are needed to investigate whether enzymes other than GST are activated in rice by Z-ligustilide to detoxify S-metolachlor.

\section{Conclusion}

Z-ligustilide extracted from $L$. chuanxiong detoxifies the herbicide S-metolachlor when applied to rice through an increase in GST activity, suggesting its use as a potential herbicide safener.

\section{Acknowledgements}

This research was funded by national science research projects of China (No.201303031 and 31501661), Hunan Leading Academic Discipline Project (No. 090403), and Open-End Fund of the Inovative College Plantform of Hunan (No. 13K116 and 13K115).

\section{References}

Bussler, B.H., 1996. Safening Herbicidal Pyrazolylsulfonylureas. US Patent office: 5502025[P], United States

Brazier, M., D.J. Cole and R. Edwards, 2002. O-Glucosyltransferase activities toward phenolic natural products and xenobiotics in wheat and herbicide-resistant and herbicide-susceptible black-grass (Alopecurus myosuroides). Phytochemistry, 59: 149-156

Cui, F., L. Feng and J. Hu, 2006. Factors affecting stability of z-ligustilide in the volatile oil of radix Angelicae sinensis and Ligusticum chuanxiong and its stability prediction. Drug Dev. Ind. Pharm., 32: 747-755
Cummins, I., D.N. Bryant and R. Edwards, 2009. Safener responsiveness and multiple herbicide resistance in the weed black-grass (Alopecurus myosuroides). Plant Biotechnol. J., 7: 807-820

Chu, S.S., G.H. Jiang and Z.L. Liu, 2011. Insecticidal components from the essential oil of Chinese Medicinal Herb, Ligusticum chuanxiong Hort. Eur. J. Chem., 8: 300-304

Davies, J and J.C. Caseley, 1999. Herbicide safeners: a review. Pestic. Sci., 55: 1043-1058

DeRidder, B.P., D.P. Dixon, D.J. Beussman, R. Edwards and P.B. Goldsbrough, 2002. Induction of glutathione S-transferases in Arabidopsis by herbicide safeners. Plant Physiol., 130: 1497-1505

Deridder, B.P. and P.B. Goldsbrough, 2006. Organ-specific expression of glutathione S-transferases and the efficacy of herbicide safeners in Arabidopsis. Plant Physiol., 140: 167-175

Deng, F. and K.K. Hatzios, 2002a. Characterization and safener induction of multiple glutathione S-transferases in three genetic lines of rice. Pestic. Biochem. Phys., 72: 24-39

Deng, F. and K.K. Hatzios, 2002b. Purification and characterization of two glutathione S-transferase isozymes from indica-type rice involved in herbicide detoxification. Pestic. Biochem. Phys., 72: 10-23

Deng, F. and K.K. Hatzios, 2003. Characterization of cytochrome P450mediated bensulfuron-methyl O-demethylation in rice. Pestic. Biochem. Phys., 74: 102-115

Ekler, Z., F. Dutka and G.R. Stephenson, 1993. Safener effects on acetochlor toxicity, uptake, metabolism and glutathione S-transferase activity in maize. Weed Res., 33: 311-318

Gronwald, J.W. and K.L. Plaisance, 1998. Isolation and characterization of glutathione S-transferase isozymes from sorghum. Plant Physiol., 117: 877-892

Hofer, U., M. Muehlebach, S. Hole and A. Zoschke, 2006. Pinoxaden for broad spectrum grass weed management in cereal crops. J. Plant Dis. Prot., 20: 989-995

Ho, C.C., A. Kumaran and L.S. Hwang, 2009. Bio-assay guided isolation and identification of anti-Alzheimer active compounds from the root of Angelica sinensis. Food Chem., 114: 246-252

Kolukisaoglu, U.H., L. Bovet, M. Klein, T. Eggmann, M. Geisler, D. Wanke, E. Martinoia and B. Schulz, 2002. Family business: the multidrugresistance related protein (MRP) ABC transporter genes in Arabidopsis thaliana. Planta, 216: 107-119

Kramer, W. and U. Schirmer, 2007. Safener for Herbicides, Vol. 1-3, pp: 259-281. Modern crop protection compounds, Wiley, Weinheim, Germany

Leif, J.W., O.C. Burnside and A.R. Martin, 1987. Efficacy of CGA-92194 and flurazole in protecting grain sorghum (sorgbum bicolor) from herbicide injury. Weed Sci., 35: 547-553

Liu, H., 2010. Spectral characterization and chiral interactions of plant microsomal cytochrome P450 with metolachlor and herbicide safeners. J. Environ. Sci. Heal. B, 45: 33-39

Miyazawa, M., T. Tsukamoto, J. Anzai and Y. Ishikawa, 2004. Insecticidal effect of phthalides and furanocoumarins from Angelica acutiloba against Drosophila melanogaster. J. Agric. Food Chem., 52: 4401-4405

Meepagala, K.M., G. Sturtz, D.E. Wedge, K.K. Schrader and S.O. Duke, 2005. Phytotoxic and antifungal compounds from two Apiaceae species, Lomatium californicum and Ligusticum hultenii, rich sources of Z-ligustilide and apiol, respectively. J. Chem. Ecol., 31: 1567-1578

Riechers, D.E., K. Kreuz and Q. Zhang, 2010. Detoxification without intoxication: herbicide safeners activate plant defense gene expression. Plant Physiol., 153: 3-13

Sim, Y. and S. Shin, 2008. Combinatorial anti-trichophyton effects of Ligusticum chuanxiong essential oil components with antibiotics. Arch. Pharm. Res., 31: 497-502

Edwards, R., D.P. Dixon, I. Cummins, M. Brazier-Hicks and M. Skipsey, 2011. New perspectives on the metabolism and detoxification of synthetic compounds in plants, In: Organic Xenobiotics and Plants, pp: 125-148. Schröder, P. and C.D. Collins (eds.). Springer Netherlands

Wu, J.R., C.L. Cramer and K.K. Hatzios, 1999. Characterization of two cDNAs encoding glutathione S-transferases in rice and induction of their transcripts by the herbicide safener fenclorim. Physiol. Plant., 105: $102-108$

(Received 29 April 2015; Accepted 25 January 2016) 